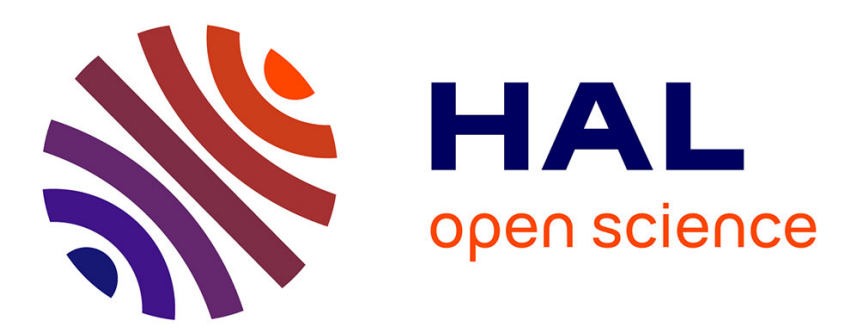

\title{
Measurement of surface recombination of excess carriers by use of the double modulation technique
}

\author{
S. Käpplinger, F. Buchmann, H. Geiler
}

\section{To cite this version:}

S. Käpplinger, F. Buchmann, H. Geiler. Measurement of surface recombination of excess carriers by use of the double modulation technique. Journal de Physique IV Proceedings, 1994, 04 (C7), pp.C7-145-C7-149. 10.1051/jp4:1994735 . jpa-00253264

\section{HAL Id: jpa-00253264 https://hal.science/jpa-00253264}

Submitted on 1 Jan 1994

HAL is a multi-disciplinary open access archive for the deposit and dissemination of scientific research documents, whether they are published or not. The documents may come from teaching and research institutions in France or abroad, or from public or private research centers.
L'archive ouverte pluridisciplinaire HAL, est destinée au dépôt et à la diffusion de documents scientifiques de niveau recherche, publiés ou non, émanant des établissements d'enseignement et de recherche français ou étrangers, des laboratoires publics ou privés. 


\title{
Measurement of surface recombination of excess carriers by use of the double modulation technique
}

\author{
S. Käpplinger, F. Buchmann and H.D. Geiler* \\ Friedrich-Schiller-University, IFK, Helmholtzweg 5, 07745 Jena, Germany \\ * Jenawave Engn. \& Consult., Friedrich-Schelling-Str. 11, 07745 Jena, Germany
}

\begin{abstract}
The well characterized (100)-Si surface subjected to low energy ion irradiation is used to demonstrate the capability of the contactless measurement of the surface recombination velocity of excess carriers by applying the photothermal response technique under high vacuum conditions. During and after the processing the photothermal response is recorded in the frequency domain. From the wide range frequency sweep surface recombination velocities between $1 \mathrm{~m} / \mathrm{s}$ up to $1000 \mathrm{~m} / \mathrm{s}$ can be extracted.
\end{abstract}

\section{Introduction}

Photothermal techniques of modulation spectroscopy [1] play a more and more important role for nondestructive and contactless evaluation of materials [2]. Recently the problems of surface and interface state densities in connection with the influence on the electrical properties are investigated by use of more refined methods of optical [3] and electrical [4] modulation techniques.
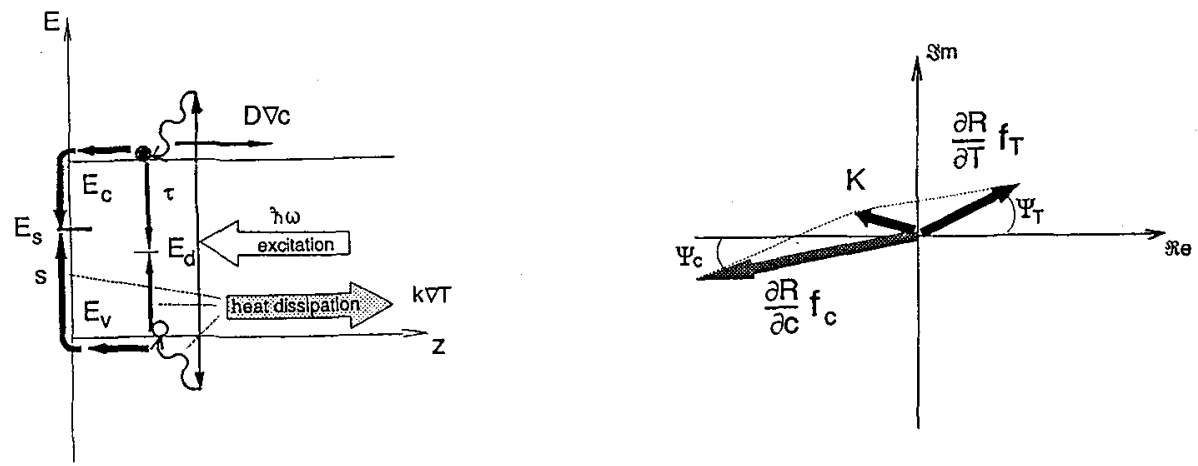

Fig.1: Scheme of the relaxation processes (left part) and the superposition of the excess carrier and thermal response $f_{c}$ and $f_{r}$, respectively, in the complex space (right part)

The measurement of the relaxation of photoexcited carriers by use of electrical contacts [5] or exploitation of free carrier absorption [6] are common [7,8]. The present paper demonstrates the capability of the photothermal double modulation [9] for semiconductor surface investigations. 


\section{BASIC EQUATIONS}

The excess carrier and thermal wave analysis of surface recombination channels is based on the following model $[10,11]$ (see fig. 1 left part): The sample is excited by the primary energy deposition from a continously intensity modulated laser beam of modulation frequency $\Omega$. The energy deposited into the electron gas dissipates via different radiationless channels (secondary energy deposition) [12]. Taking into account the excess carrier diffusion governed by the ambipolar diffusivity $\mathrm{D}$, the bulk excess carrier recombination [14] determined by the lifetime $\tau$ and the surface recombination expressed by the recombination velocity $s$ the modulated part of the carrier concentration the so called carrier or plasma wave $\hat{c}$ follows [10]:

$$
\Delta \hat{c}-p^{2} \hat{c}=-\frac{\hat{v}}{\hbar \omega D} ; p^{2}=\frac{1+i \Omega \tau}{D \tau} ; D \nabla \hat{c}(0)=s \hat{c}(0)
$$

The energy deposition function $\hat{v}$ can be deduced from the divergence of the Poynting vector of the electromagnetic laser field with the optical frequency $\omega$ [12]. The boundary condition of $\hat{c}$ at the surface on the right place of equ.(1) contains the surface recombination velocity s.

The energy stored in the electronic system dissipates due to radiationless recombination through the channels indicated in fig. 1 and causes the thermal wave $\hat{T}[8,10]$ :

$$
\Delta \hat{T}-q^{2} \hat{T}=-\frac{\hbar \omega-E_{g}}{\hbar \omega} \cdot \frac{\hat{v}}{k}-\frac{E_{8}}{k \tau} \hat{c} ; q=\sqrt{\frac{\Omega}{2 \kappa}}(1+i) ;-k \nabla \hat{T}(0)=s E_{g} \hat{c}(0)
$$

The right side of of the first part of equ.(2) describes the direct heating by intraband relaxation and the energy deposition by bulk recombination [12]. The heat dissipates via heat conduction governed by the thermal conductivity $k$. The surface recombination channel causes a heat source at the surface expressed in the boundary condition (right part of equ. (2)).

The double modulation technique [9] represents a specific reading out of the response $(\hat{c}, \hat{\mathrm{T}})$ due to the intermodulation between the two frequencies $\Omega_{1}$ and $\Omega_{2}$ of the incident laser beam (heterodyn mixing). Both frequencies are so narrowly separated that photothermal dispersion does not occur and the sample response is equivalent to an excitation by one single frequency $\Omega=\left(\Omega_{1}+\Omega_{2}\right) / 2$. Because the incident beam does not include the differential frequency and the measured signal depends quadratically on the incident laser power we introduce the complex conversion coefficient $\mathrm{K}$ as the normalized result of the response measurement. It represents that fraction of the incident power which is converted into the differential frequency by the scattering with the lateral and temporal modulated dielectric function due to a normalized complex response wave (amplitude and phase). The thermal and carrier response are normalized with the modulated power density of excitation, which is for Gaussian shaped beams of spot radius $w$ given by (1-R)P/w. Therefore the conversion coefficient $\mathrm{K}$ is measured with the unit $\left[\mathrm{mW}^{-1}\right]$. The so defined conversion coefficient represents the link to the theoretical interpretation:

$$
\begin{aligned}
K & =\frac{1}{4 \pi} \frac{1}{\bar{R}} \frac{\partial R}{\partial T} \cdot \int_{0}^{\infty} \lambda^{\prime} d \lambda^{\prime} e^{-\frac{1}{2} \lambda^{2}}\left\{\Re\left(\hat{t}_{\lambda^{\prime}}\right)-i \Re\left\{t_{\lambda^{\prime}}\right\}\right\} \\
& +\frac{1}{4 \pi} \frac{1}{\bar{R}} \frac{\partial R}{\partial c} \cdot \int_{0}^{\infty} \lambda^{\prime} d \lambda^{\prime} e^{-\frac{1}{2} \lambda^{2}}\left\{\Re\left\{\hat{c}_{\lambda^{\prime}}\right\}-i \Im\left\{\hat{c}_{\lambda^{\prime}}\right\}\right\}
\end{aligned}
$$

The Bessel transformed excess carrier wave $\hat{c}_{\lambda}$ and thermal wave $\hat{t}_{\lambda}$ as a function of the space frequency $\lambda$ are normalized to the excitation power for Gaussian shaped laser beams of spot size 
w [13]. In the deposition region the response waves are convoluted laterally by the intensity profile of the laser beam.

$$
\begin{gathered}
K=\frac{1}{\bar{R}} \frac{\partial R}{\partial c} \frac{1}{\hbar \omega D} \cdot\left[-F_{c}+b \cdot F_{T}\right] \quad, \quad b=\frac{4 \pi^{2} \epsilon_{o} m c^{3} \overline{n h}}{\lambda^{3} e^{2}} \cdot \frac{D}{k} \cdot \frac{\partial n}{\partial T} \\
F_{T c}=-F_{c}+b \cdot F_{T}
\end{gathered}
$$

For abbreviation we introduce the dimensionless carrier and thermal sweep functions $\mathrm{F}_{\mathrm{c}}(\Omega)$ and $\mathrm{F}_{\mathrm{T}}(\Omega)$, respectively, representing this lateral integrals [13].

In the signal both waves are coupled by the coupling factor $b$ (see fig. 1 right part), which is calculated from the free carrier absorption by use of the Drude model with the consequence of the negative sign in front of $F_{c}[11,15]$ : The joint sweep function $F_{\mathrm{Tc}}$ is calculated using the material parameter of our silicon samples. For the optical wave lengths $\lambda=514 \mathrm{~nm}$ and $\lambda=785 \mathrm{~nm}$ the coupling factors are $b=2.81$ and $b=$. 0.78 , respectively, which is in good agreement with the experiment.

In fig.2 the calculated complex sweep function is presented as a circle plot (upper part) and plotted as a sweep curve versus $1 / \sqrt{ } \Omega$ (lower part). Each circle plot starts for high frequencies in the third quadrant (carrier wave domaine) fitting the $y=x$-line and ends for the frequency 0 on the real axix in the second or first quadrant depending on the radiationless losses (carrier wave domain or thermal wave domain, respectively).

\section{SAMPLE PREPARATION AND PROCESSING}

For the investigation of the surface by photothermal methods well characterized (100)-silicon wafer

( $5 \Omega \mathrm{cm}, \mathrm{D}=5.8 \mathrm{~cm}^{2} \mathrm{~s}^{-1}, \tau=10 \mu \mathrm{s}$, $\kappa=0.89 \mathrm{~cm}^{2} \mathrm{~s}^{-1}$ ) were selected and their surfaces prepared with two different types of oxides:

a) native oxide grown after the HFdip immediately before loading the UHV-chamber,
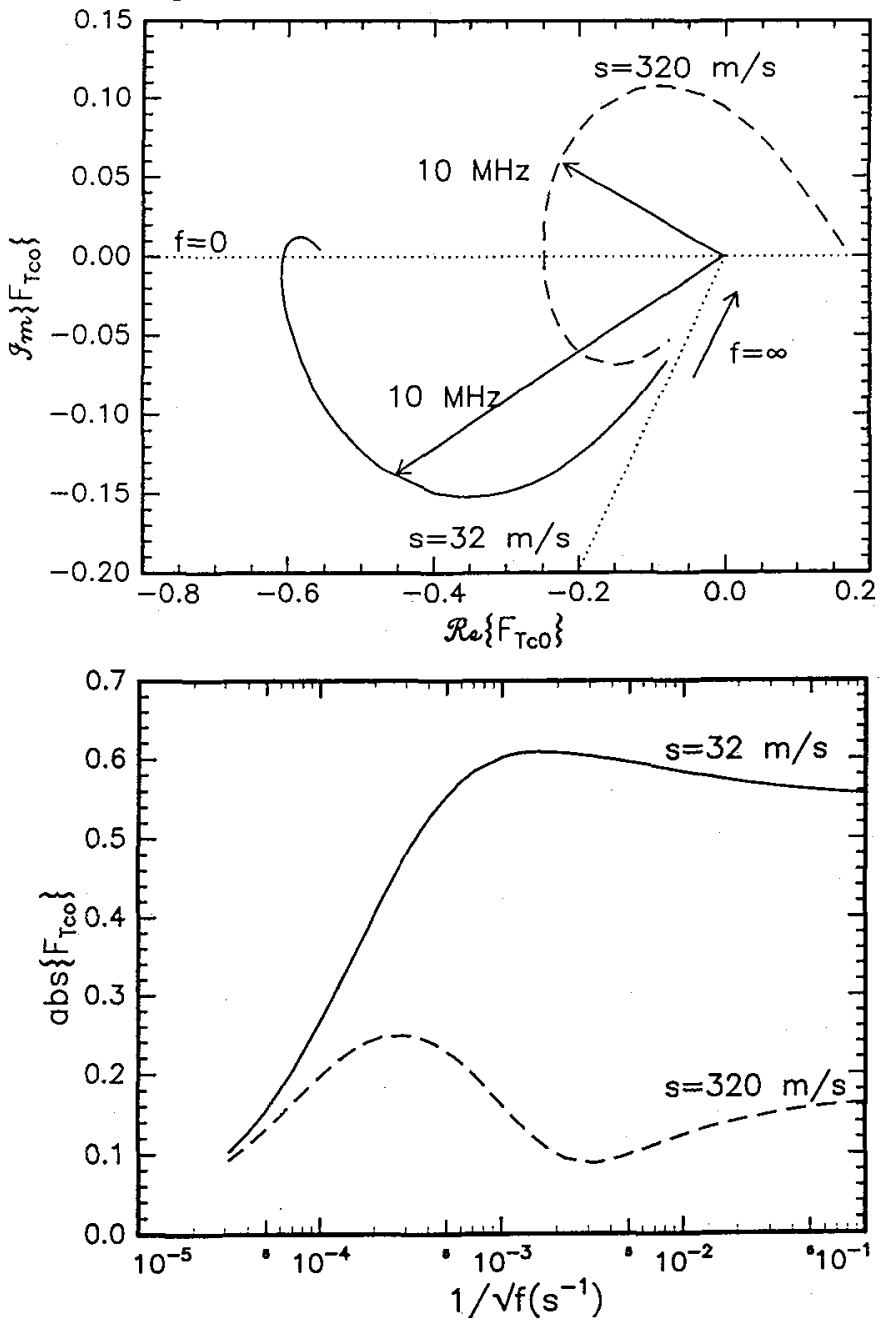

Fig.2: Calculated circle plot (upper part) and the corresponding sweep curve $(100 \mathrm{~Hz}-1 \mathrm{GHz})$ of the conversion coefficient (lower part) of silicon for different surface recombination velocities $\mathbf{s}$. 
b) $25 \mathrm{~nm}$ gate oxide grown by standard gate oxidation procedure.

The surface of the sample was modified by electron irradiation $(E=2 \mathrm{KeV})$ and low energy $\mathrm{N}^{+}$-ion bombardement $(E=300 \mathrm{eV})$ in the vacuum chamber. The change of the recombination velocity of the excess carriers is investigated after irradiation by measuring the conversion coefficient versus the modulation frequency by use of the thermal wave inspection system TWIN (Jenoptik GmbH Jena). The effective radius $w$ of the laser spot on the sample was determined to be $3.2 \mu \mathrm{m}$.

Due to the sensitive balance between the contributions of carrier and thermal wave to the conversion coefficient surface recombination velocities in the range of about $50 \mathrm{cms}^{-1}$ up to $10^{5} \mathrm{cms}^{-1}$ can be measured using the zero determination of the real or imaginary part (see the circle plots in fig.2). Because the method is insensitive for smaller recombination velocities the gate oxide samples were used for zero point calibration of the recombination velocity.

The investigation is focused on the influence of ion irradiation on the surface recombination due to defect generation. The irradiation was carried out in a dose range between $10^{7} \mathrm{~cm}^{-2}$ and $5 \times 10^{14} \mathrm{~cm}^{-2}$ with

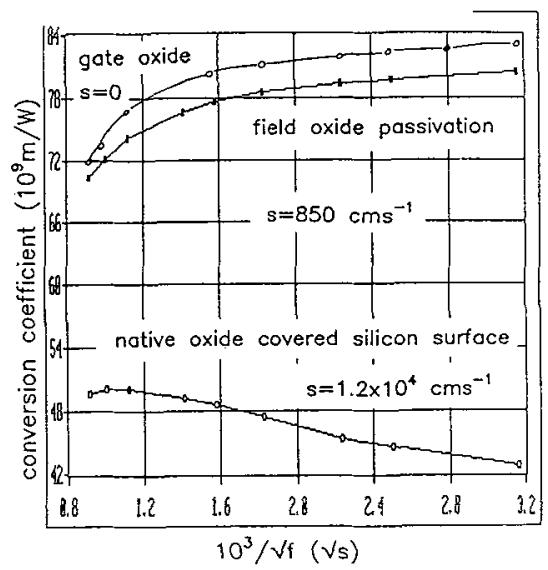

Fig.3: Conversion coefficient versus modulation frequency for different types of surface passivation of silicon

\section{RESULTS AND DISCUSSION}

The measured conversion coefficients of the silicon samples after different stages of surface preparation are shown in fig.3. With increasing surface recombination the carrier wave decreases

and the thermal wave increases hence the amplitude of the conversion coefficient goes through a minimum from the carrier wave domain into the thermal wave dommain (see fig. 2). The sweep curves demonstrate the well known fact that gate oxide covered silicon surfaces show a smaller surface recombination than native oxide covered ones. The ion processing was carried out with the native oxide covered surface. In fig. 4 the measured circle plots of the conversion coefficients

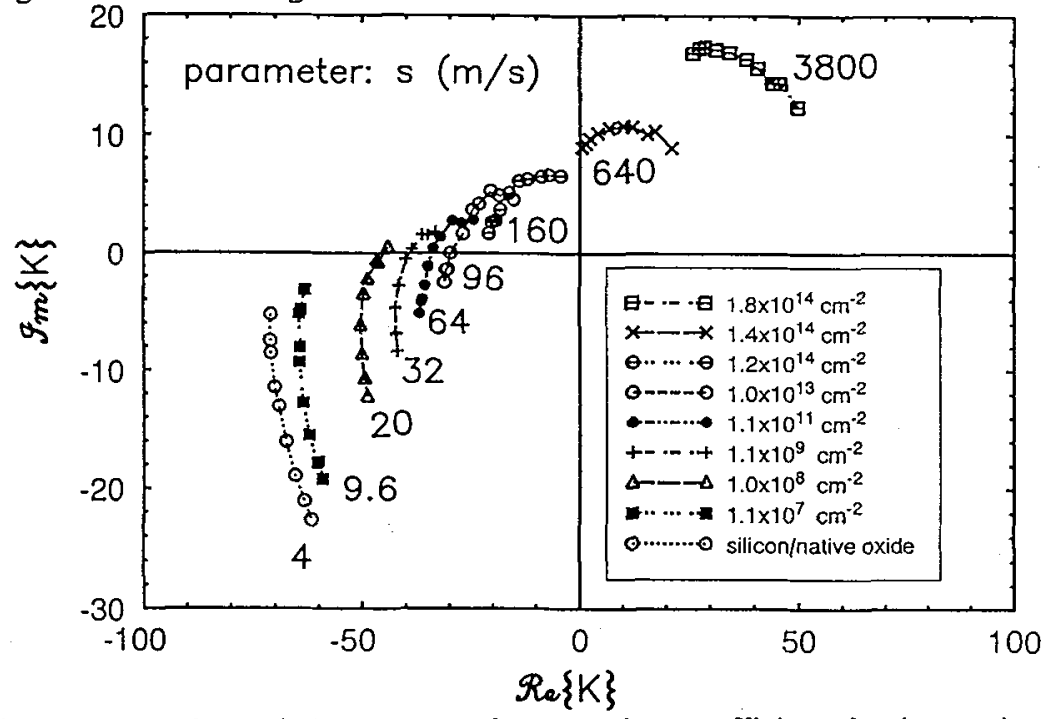

Fig.4: Circle plots of the measured conversion coefficient for increasing dose of $\mathrm{N}^{+}$-irradiation (see inlay) and the extracted corresponding values of the surface recombination velocity $\mathrm{s}$. 
depending on the irradiation dose are collected representing the changes of the surface state in correlation with the increasing ion dose. Because of the very low ion energy only two monolayers were changed by the irradiation. This damage only influences the surface recombination. To get a more quantitative understanding the combinated sweep form function $F_{T c}$ is calculated numerically using the material parameter given above. All lengths scale with the laser spot radius $w$. For fixed bulk parameters the value $s / w$ can easily be determined from the condition for the zeros of the real or imaginary part of $\mathrm{F}_{\mathrm{Tc}}$

$$
-F_{c}\left(s, \Omega_{o}\right)+b \cdot F_{T}\left(s, \Omega_{o}\right)=0
$$

Equ.(5) gives the relation between $s$ and the frequency of the zero $\Omega_{\mathrm{o}}$. For small bulk recombination (excess carrier lifetime $>10 \mu \mathrm{s}$ ) this transzendent equation governing $\mathrm{s}\left(\Omega_{\mathrm{o}}\right)$ can be approximated by a linear relation between $s$ and $\sqrt{ } \Omega_{0}$, becausse it becomes insensitive of $\tau$. With the measured value of the gate oxide covered surface used as the normal for $\mathrm{s} / \mathrm{w}=0 \mathrm{~s}^{-1}$ this gives the calibration curve for an absolute measurement of $s /(D w)$. All values are extracted from this relation.

Acknowledgement: The authors thank the Jenoptik $\mathrm{GmbH}$ for the instrumental support.

\section{References}

[1] B.Batz, in "Semiconductors and Semimetals " Vol.9 ,ed. by R.K.Willardson and A.C.Beer, Academic Press 1972, p.315

[2] G.Busse, H.G.Walther, in "Principles and Perspectives of Photothermal and Photoacoustic Phenomena", ed by A.Mandelis, Elsevier New York 1992, p.205

[3] B.C.Forget, D.Fournier; in "Photoacoustic and Photothermal Penomena III", ed. by D.Bicanic; Springer Series in Optical Sci. Vol.69, Springer-Verl. Berlin 1992 p.375

[4] N.M.Ravindra, O.L.Russo, D.Fathy, J.Narayan, A.R.Heyd, K.Vedam; in Mat.Res.Soc.Symp.Proc. Vol.105, ed.by S.T.Pandelides, G.Lucovsky; Pittsburgh 1988, p.169

[5] E.Suzuki, Y.Hayashi; J.Electrochem.Soc. 139(1992)1741

[6] A.Usami, H.Fujiwara, T.Nakai, K.Matsuki, T.Takeuchi, T.Wada; IEICI Transactions on Electronics E75-C(1992)978

[7] C.Fujihira, M.Morin, H.Hashizume, J.Friedt, Y.Nakai M.Hirose; Jap.J.Appl.Phys. 32(1993)L1362

[8] A.N.Petrovsky, A.O.Salnick, V.V.Zuev, D.O.Muhkin, M.M.Mehktiev, J.Pelzl, A.C.Boccara, D.Fournier; in "Photoacoustic and Photothermal Phenomena III", ed. by D.Bicanic, Springer Series in Optical Sci. Vol.69, Springer Berlin 1992, p.396

[9] M.Wagner, H.D.Geiler ; Meas.Sci.Technol. 2(1991)1088

[10] A.C.Boccara, D.Fournier; in "Photoacoustic and Thermal Wave Phenomena in Semiconductors"; ed.by A.Mandelis, North Holland ,New York 1987, p.288

[11] A.Rosencwaig; in "Photoacoustic and Thermal Wave Phenomena in Semiconductors"; ed.by A.Mandelis, North Holland ,New York 1987, p.98

[12] H.D.Geiler; Nucl.Instr.\& Meth. B65(1992)9

[13] M.Vaez Iravani, H.K.Wickramasinghe; J.Appl.Phys. 58(1985)122

[14] H.D.Geiler, S.Krügel, J.Nützel, E.Frieß, G.Abstreiter; Appl.Surf.Sci. 63 (1993)260

[15] R.Wagner, A.Mandelis; J.Phys.Chem.Sol. 52(1991)1061 